\title{
Effects of Ten Weeks Table Tennis Training on Dynamic Visual Acuity 十週規律桌球蓮動訓練對人體動體視力之影響
}

\author{
Kun-Yung LIN ${ }^{1}$ Alex, J. Y. LEE ${ }^{1}$ Wei-Hsiu LIN $^{2}$ Ya-Chen LIU $^{3}$ \\ ${ }^{I}$ Department of Physical Education, \\ National Hsin-Chu University of Education, TAIWAN \\ ${ }^{2}$ Department of Physical Education, \\ National Chia-Yi University, TAIWAN \\ ${ }^{3}$ Office of Physical Education, \\ Chung-Hua University, TAIWAN
}

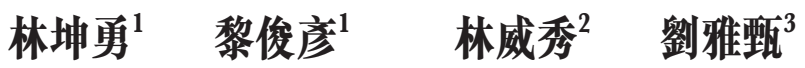 \\ 台灣國立新竹教育大學體育學系 \\ 台灣國立嘉義大學體育學系 ${ }^{2}$ \\ 台灣中華大學體育室 ${ }^{3}$
}

\begin{abstract}
The purpose of this study was to investigate the effects of ten weeks table tennis training on dynamic visual acuity (DVA) on general population. Fourteen collegiate students were volunteered and ransom assigned equally as training group or control group. Training group underwent a ten weeks table tennis training program with 500 balls twice a week, but control group did not received any kind of exercise training during this period. DVA was measured with commercial software Athlevision to evaluate in four directions: right, left, up, and down, and calculated as horizontal (DVA-H), vertical, and total (DVA-T) abilities. Results reveal that training group showed significant improved DVA abilities in DVA-L (2.29 \pm 0.49 vs. 3.14 \pm 0.69 , F $=7.09, \mathrm{p}<.05)$, DVA-H $(4.71 \pm 0.76$ vs. $6.29 \pm 1.25, \mathrm{~F}=9.64, \mathrm{p}<.05)$, and DVA-T $(9.57 \pm 0.98$ vs. $11.29 \pm 1.60, \mathrm{~F}=6.17, \mathrm{p}$ $<.05)$ after ten weeks table tennis training. The finding suggested that ten weeks regular table tennis training can improve the DVA ability on general population. It is possible that during this training, participants have to continual focusing/tracking the moving ball, and correctly predict the distance/space between the line, net, and the direction of coming ball, therefore, improved the rapid senses of fovea and the control of oculomotor system.
\end{abstract}

Key Words: sports vision, visual acuity, fast-ball events.

\section{摘 要}

本研究目的在於探討十週規律桌球運動訓練對人體動體視力的影響。14位大學生自願參與並隨機分為桌球訓練組與一般組, 桌球訓練組需進行連續10週, 每週2次, 每次500球之桌球訓練, 一般組則無接受任何運動訓練, 兩組皆於訓練前後以Athlevision測 試軟體評估其動體視力的變化。結果發現訓練後桌球組向左 ( $2.29 \pm 0.49$ 等級 vs. $3.14 \pm 0.69$ 等級, $F=7.09, p<.05)$ 、水平 $(4.71 \pm 0.76$ 等 級 vs. $6.29 \pm 1.25$ 等級, $F=9.64, p<.05)$ 與整體 $(9.57 \pm 0.98$ 等級 vs.11.29 \pm 1.60 等級, $\mathrm{t}=6.17, \mathrm{p}<.05)$ 等動體視力表現有顯著改善。結論 : 規律桌球訓練可改善人體的動體視力表現, 其機轉應與桌球訓練時需以視覺持續注視或追蹤高速旋轉移動的球體, 且要正確判斷 持拍與來球之間的距離、邊端線、網子與對方的位置，因而提升眼球中央小窩快速移動球體知覺與眼球控制能力。

\section{關鍵詞：運動視覺、視覺敏鋭性、快速球體運動}




\section{壹、緒論}

桌球是一種具正面健身效益與豐富嬠樂效果的運動, 因 其績較不易受到選手身材、體型的影響，而所需之裝備費用 與場地限制也較少, 且非常適合老年人與幼小孩童從事, 是 一種很適合東方人發展的運動項目, 數十年來亞洲選手在國 際桌球賽事成績皆非常優異, 因此桌球非常適合發展與培訓 的重點運動項目之一。

動體視力(dynamic visual acuity, DVA)是結合眼睛的視 動系統 (oculomotor system) 解析能力, 並經由中樞神經系統 來預測移動中物體的速度, 以獲得辨識物體細微結構與清晰 見物的能力 (Miller \& Ludvigh, 1962), 因需將物體影像保 持在中央小窩處, 使視動系統與眼球運動能力有關。先前的 研究指出具快速球類特性運動(如棒球、網球、板球、羽球與 籃球)之選手, 較其他不需追蹤快速移動物體運動之選手, 需 較高的視覺能力需求, 並會影響到其運動技能之表現 (Ishigaki \& Miyao, 1993 \& 1994; Maeda \& Tsuruhara, 1998; Liu et al., 2007; Liu, et al., 2010; Wang \& Liu, 2011), 因為 其需依快速移動球體的動向, 來進行相對應的肢體反應與動 作。

桌球是一種快速的球類運動, 在一顆直徑只有 40 公呚 的桌球球體, 接球者要能成功的回擊快速接近之桌球, 不僅 需有優異的視覺系統, 以精確的觀察移動中球體的位置、軌 跡與速度, 同時也要能迅速的判斷最適合回擊之空間位置與 時機球, 因此動體視力對於桌球選手而言應該是非常重要的 視覺能力。先前有關桌球運動的相關研究, 大多著重在心理 策略、技戰術、教學訓練、比賽制度與球拍材質等, 尚未有 研究探討桌球訓練對人體動體視力之可能影響, 因此, 本研 究之目的在探討 10 週規律桌球運動訓練對人體動體視力之影 響。

\section{武・方法}

\section{一、研究對象}

14 位非桌球專項且未參與規律桌球訓練的健康大學生 $(4$ 男 10 女, 平均年齡 $19.57 \pm 0.90$ 歲; 平均身高 $159.85 \pm 7.34$ 公 分; 平均體重 $53.57 \pm 6.34$ 公斤) 自願參與本研究, 隨機分派為 男女人數均等之桌球組與一般組, 桌球組需接受十週多球訓 練而一般組則無接受任何運動訓練, 所有參與者在實驗期間 需維持日常之身體活動與生活習慣, 於實驗前詳閲研究計劃 須知, 填寫健康情沉調查表、研究參與同意書與基本資料。

\section{二、桌球訓練處方}

本研究桌球訓練處方為持續十週, 每週 2 天且每次訓 練時間為1小時的桌球多球訓練計畫。送球者須具備中華民 國桌球協會B級教練檢核通過, 以多球練習方式進行回擊訓 練, 並依一般訓練要點與擊球者之能力, 來適性調整送球之 速度與方向, 進行定點正點或反手擊球。訓練期前三週為定 點正手攻球 (500顆球)，第四週至第七週為二分之一球橲正 手攻球 (前二週為 600 顆球, 其後為 800 顆球), 第七週至第十 週則為全橲不定點正手攻球 (第七週為900顆球, 第八週與第 九週為 1000 顆球)。

\section{三、動體視力評估}

本研究 D V A 測試是使用專業運動視覺測試軟體 Athlevision(Asics Corp., 2003), 來分別測試個體辩識向右 動體視力 (DVA-R)、向左動體視力 (DVA-L)、向下動體視力 (DVA-D)與向上動體視力(DVA-U) 快速移動的數字之辨識能 力。為避免太陽光線影響測試電腦螢幕的亮度與出現反光, 而影響受試者的辦識, 所以實驗皆是於室內同一位置與同台 電腦設備來進行, 並依照測試軟體之規範來進行測試, 測試 過程中研究參與者可使用矯正視力之眼鏡, 但身體與頭部均 不能移動, 以減少實驗誤差。

每位參與者均經詳細解説DVA軟體之測試方法與流程 解説, 在四種動體視力測試前均有三次的練習, 以熟悉實 驗儀器和測驗流程, 才進行正式之動體視力測試。研究者於 開始正式測試前説預備, 要求受試者專心注視電腦, 此時電 腦會顯示二半圓, 並於中間軌道出現三個數字, 此數字會以 不同速度移動並隨機變換三個數字, 參與者必需辨識所出現 的三個數字為何, 而不論回答是否正確, 研究者均不得告知 正確數字, 以避免產生學習效果及影響受試者心理狀態。當 每個方向的測試結束後, 皆會給予參與者適當之休息與準備 時間。所有參與者在訓練前進行第一次測試(前測)，而訓練 十週後再測試第二次(後測)。本研究參考先前研究設定與資 料分析方式, 將DVA-R 與DVA-L相加來作為水平動體視力 (DVA-H)之代表; 將DVA-U與DVA-D相加來作為垂直動體視 力(DVA-V)之代表; 將DVA-H 與DVA-V相加來作為整體動體 視力(DVA-T)之代表。

\section{四、統計分析}

本研究所得數據皆以平均數土標準差來表示, 以訓 練前動眼視力各參數為共變量, 進行單因子共變數分析 (ANCOVA), 以比較十週桌球多球訓練後兩組DVA各項參數 之差異。本研究以SPSS for Windows 12.0中文版進行統計 程式分析處理，統計考驗㙷著水準皆定為 $\mathrm{p}<.05$ 。 


\section{參、結果}

本研究結果如表1所示, 所有參與者未訓練前四種方向 之動體視力表現等級介於 2.29 至 2.57 , 經換算後水平、垂直 與整體動體視力表現等級則分別為4.71、4.86與 9.57 ; 而經由 十週規律桌球訓練後, 所有參與者四種方向之動體視力表現
等級介於 2.14 至 3.14 , 經換算水平、垂直與整體動體視力表 現等級分別為6.29、5.00與11.29。所得數據經單因子共變數 統計分析, 顯示桌球組於十週桌球多球訓練後可顯著提昇向 左 $(F=7.09, p<.05)$ 、水平 $(F=9.64, p<.05)$ 與整體 $(F=6.17$, $\mathrm{p}<.05)$ 等動體視力表現; 但在一般組則未發現有任何顯。

表1. 十週桌球訓練組與一般控制組前測與後測DVA表現

\begin{tabular}{|c|c|c|c|c|c|}
\hline 變 項 & 前測 & 後測 & 前測 & 後測 & $\mathrm{F}$ 值 \\
\hline DVA-R & $2.43 \pm 0.79$ & $3.14 \pm 1.07$ & $21.4 \pm 0.90$ & $2.29 \pm 0.76$ & 3.44 \\
\hline DVA-L & $2.29 \pm 0.49$ & $3.14 \pm 0.69 *$ & $2.43 \pm 0.79$ & $2.29 \pm 0.76$ & 7.09 \\
\hline DVA-D & $2.57 \pm 0.53$ & $2.86 \pm 0.69$ & $2.29 \pm 0.76$ & $2.29 \pm 0.95$ & 0.91 \\
\hline DVA-U & $2.29 \pm 0.49$ & $2.14 \pm 0.38$ & $2.29 \pm 0.95$ & $2.43 \pm 1.27$ & 0.85 \\
\hline DVA-H & $4.71 \pm 0.76$ & $6.29 \pm 1.25^{*}$ & $4.57 \pm 1.51$ & $4.57 \pm 1.27$ & 9.64 \\
\hline DVA-V & $4.86 \pm 0.69$ & $5.00 \pm 0.82$ & $4.57 \pm 1.27$ & $4.71 \pm 2.06$ & 0.19 \\
\hline DVA-T & $9.57 \pm 0.98$ & $11.29 \pm 1.60 *$ & $9.14 \pm 1.95$ & $9.29 \pm 2.69$ & 6.17 \\
\hline
\end{tabular}

註: 所有數據以平均數土標準差來表示, *代表 $p<.05 ;$ DVA-R : 向右動體視力, DVA-L : 向左動體視力, DVA-D : 向下動體視力, DVA-U : 向上動體視力, DVA-H : 水平動體視力, DVA-V : 垂直動體視力, DVA-T : 整體動體視力。

\section{肆、討論}

DVA 是指個體正確辨識移動中物體細微部分的能力, 需同時結合眼睛的解析能力與動眼系統能力 (oculomotor system), 來將物體影像持續的保持於中央小窩, 以精確辨識 物體的細微結構(Hoffman et al., 1981)。本研究顯示非桌球 專長之一般大學生, 經十週桌球多球訓練後, 可顯著提昇向 左(DVA-L)動體視力、水平 (DVA-H)動體視力與整體動體視 力(DVA-T)表現, 而未經訓練一般組之DVA表現則無顯著變 化, 顯示此種多球訓練對DVA表現之正面增進效益。由於中 央小窩(fovea)分佈最多的視錐細胞, 為了清楚辯識快速移動 的物體, 眼睛必須藉由慢速的隨意追蹤運動 (slow voluntary pursuit movement) 與快速的急動運動 (saccadic movement), 以保持物體影像於中央小窩, 因此訓練後顯著提昇之動體視 力表現, 應與訓練後眼球中央小窩較能快速知覺到移動的球 體, 特別是在水平與向左方向的移動變化, 以及較佳的眼球 控制能力有關。

本研究運動測試軟體的內建常模顯示, 當單一方向動體 視力的測試結果低於等級 2 以下時, 評定為低於常人; 若介 於等級 2 至 5 , 評定為一般常人; 若介於等級 6 以上, 評定為
達運動員水準。本研究結果顯示參與者未訓練前, 向左、向 右、向上與向下皆大於等級 2 , 且水平、垂直與整體動體視 力 (DVA-H)等級約為4.7、4.9與9.6，與Liu(2004)以年齡 10 至 26 位222位健康受試對象所得之測試數據相似, 驗證本研究 參與者之動體視力水準屬於正常等級。然而在十週規律桌球 訓練後, 本研究結果顯示水平、垂直與整體動體視力(DVAH)等級約為6.3、5.0與11.3，參照 $\operatorname{Liu}(2006)$ 針對不同棒球球齡 選手動體視力發展特徵之結果, 則顯示出與已接受棒球訓練 2至4年之運動員有相似的動體視力表現, 其機轉應與長期訓 練與比賽需反覆的以視覺追蹤快速移動之球體, 進而發展出 較佳的動體視力。

規律的運動練習, 不僅可發展出該類運動的特殊技 能, 同時也會發展肢體平衡與動作協調性, 且視覺系統也 會學習追蹤球體與預測球路等能力, 先前研究顯示：(一) DVA表現與追蹤物體的時間呈正比, 而與追蹤物體的速 度及個體年齡呈反比; (二) 優秀運動員與男性個體之DVA 表現較非運動員與女性個體佳; (三) DVA表現會於青春前 期(early adolescence) 達穩定 (Ishigaki \& Miyao, 1993 \& 1994; Meeuwsuen et al., 1995; Millslagle, 2000; Liu \& Yang, 2005), 而Liu(2008)探討棒球投手與野手之動體視力 
與其投球與打擊表現之相關, 也開創性發現投手投球表現與 DVA-L和DVA-H有顯著關係, 而野手打擊表現則與DVA-R和 DVA-V有顯著關係, 驗證了不同運動專項選手對動體視力的 需求有其獨特性, 並建議教練與選手可嘗試加強不同的動體 視力來改善運動表現。

Maeda \& Tsuruhara (1998) 以不同等級棒球選手為研 究對象, 進行為期一年的速球打擊訓練, 結果發現訓練後 棒球選手的動體視力顯著提昇, 且顯示出顯著提高的四死球 率, 與顯著降低的三振比率; 而本研究結果則顯示十週規律 桌球訓練可顯著提昇個體動體視力的表現, 特別是在水平方 向, 不僅驗證了動體視力具可訓練性, 驗證桌球多球訓練也 如同棒球等其他視覺訓練方法, 有助於改善個體的DVA。 Millslagle et al. (2005) 指出運動訓練可刺激網狀活化系統 (reticular activating system), 並增進視覺系統的敏鋭性, 而 使個體對於視覺刺機能更警覺與準備充分, 而改善個體於 運動時的眼球、視網膜 (retinal) 與視覺等功能。本研究所採 用之桌球多球訓練不論是在接球與回擊時, 皆需個體的視覺 系統與追蹤控制功能, 精確的接收來球觸桌飛行過程中的位 置、軌跡與速度等訊息, 並由大腦皮質作出正確且迅速的反 應, 以適當的接球與回擊; 此外本研究桌球擊球時皆是在個 體側邊進行回擊動作, 因此顯著提昇的向左動體視力表現, 似乎暗示此類側邊擊球運動對動體視力之訓練效果, 可能具 有擊球側邊特殊性的差異, 然而仍需後續的研究來加以驗 證。

影響動體視力的因素主要可分為個體特質與刺激物變 數。在個體特質部分, 包括了個體本身的視網膜解析力、 週邊知覺、視動能力等因素外, 以及年齡、性別與不同專 項運動技能表現; 而有關刺激物變數部分, 則包含刺激物 的呈現時間、體積大小、移動範圍與移動速度等 (Long \& Crambert, 1990; Ishigaki \& Miyao, 1994), 此兩大因素皆 會導致個體視覺系統與中樞神經系統功能與結構的變化, 並 造成不同的知覺能力與訊息處理之表現, 而顯著的影響動體 視力的表現。考量本研究個體特徵與實際運動情境中球體變 化較小, 因此桌球的移動速度便是顯著影響運動員動體視力 表現優略的重要因素, 這也解釋了為何快速球類運動項目(如 棒球、網球、與球與籃球等) 之運動員需要較高的視覺能力 要求 (Millslagle, 2000; Millslagle, et al., 2005; Liu et al., 2007; Liu, et al., 2010; Wang \& Liu, 2011), 這是因為視 覺器官的敏感性會影響運動員的反應時間, 並進而影響臨場 運動表現。

本研究驗證桌球多球訓練可有效的改善個體的動體視力 表現, 其原因應與桌球訓練需以視覺持續且多向的追蹤高速 旋轉移動的球體, 且需正確判斷持拍與來球之間的距離、邊 端線、網子與對方的位置等, 以及大多是在個體右側進行擊 球, 因而顯示出顯著提昇的向左與水平動體視力表現。此外 訓練後顯著提昇之動體視力表現, 應與訓練後眼球中央小窩 能快速知覺移動球體，與較佳的眼球控制能力有關。
本研究驗證十週桌球訓練對人體視覺系統的效益, 此成 果應進一步的將動體視力評估應用於桌球訓練與選材上，以 有效提昇桌球選手之訓練成效，與鼓勵國人從事桌球運動之 興趣。建議後續相關研究應嘗試徵召更多的參與者, 並針對 具速球運動特性之不同專項, 來探討不同訓練模式對動體視 力參數的影響與機轉, 以進一步的將動體視力評估應用於專 項訓練與運動選材上，並建立簡便、有效且易行之動體視力 訓練計畫, 以有效改善或維持莘莘學子的動體視力, 應該也 是相當有趣與富有意義課題。

\section{參考文獻}

Hoffman, L. G., Rouse, M., \& Ryan, J. B. (1981). Dynamic visual acuity: a review. Journal of the American Optometric Association, 52, 883-887.

Ishigaki, H., \& Miyao, M. (1994). Implications for dynamic visual acuity with changes in age and sex. Perceptual and Motor Skills, 78, 363-369.

Ishigaki. H., \& Miyao, M. (1993). Differences in dynamic visual acuity between athletes and non-athletes. Perceptual and Motor Skills, 77, 835-839.

Liu, Y. C. (2004). Effect of age on development of dynamic visual acuity. Journal of Physical Education in Higher Education, 6(3), 157-165.

Liu, Y. C., Lin, T. H., \& Lin, C. K. (2007). The differences of dynamic visual acuity between baseball and karate players at various learning stages. Sports Coaching Science, 8, 133-139.

Liu, Y. C., Wang, A. L., \& Jeng, F. F. (2010). Comparison of Dynamic Visual Acuity between Open-skilled and Close-skilled Athletes. Journal of Sports Research, 19(1), 131-140.

Liu,Y. C. (2006). Characteristic of developing dynamic visual acuity by different baseball training period. Physical Education Journal National Society of Physical Education, 39(2), 41-50.

Liu,Y. C. (2008). The Relationship Between Pitching with Dynamic Visual Acuity and Batting Performance in Baseball Players. Journal of Physical Education in Higher Education, 10(1), 89-98. 
Liu,Y. C., \& Yang, S. M. (2005). A comparison to dynamic visual acuity among four-stage members of the national baseball team. Journal of Physical Education in Higher Education, 7(3), 287-294.

Long, G. M. (1994). Exercises for training vision and dynamic vilual acuity among college students. Perceptual and Motor Skills, 78, 1049-1050.

Long, G. M., \& Crambert, R. F. (1990). The nature and basis of age-related changes in dynamic visual acuity. Psychology and Aging, 5, 138-143.

Long, G. M., \& Johnson, D. M. (1996). A comparison between methods for assessing the resolution of moving targets (dynamic visual acuity). Perception, 25, 1389-1399.

Maeda, A., \& Tsuruhara, T. (1998). Effect of batting practice by using high speed pitched balls on kinetic visual acuity of baseball players. Training Science, $10,35-40$.

Meeuwsuen, H. J., Goode, S. L., \& Goggin, N. L. (1995). Coincidence-anticipation time. Women in Sport and Physical Activity Journal, 4, 59-75.

Miller, J., \& Ludvigh, E. J. (1962). The effect of relative motion on visual acuity. Survey of Ophthalmology, 7, 83-116.

Millslagle, D. (2000). Dynamic visual acuity and coincidence-anticipation timing by experienced and inexperienced women players of fast pitch softball. Perceptual and Motor Skill, 90, 498-504.

Millslagle, D., Delarosby, A., \& Vonbank, S. (2005). Incremental exercise in dynamic visual acuity. Perceptual and Motor Skill, 101, 657-664.

Wang, A. L., \& Liu, Y. C. (2011). Comparison to Dynamic Visual Acuity among Different sports events of Female athletes. Physical Education Journal National Society of Physical Education, in press.

\section{主要連絡者}

\begin{tabular}{lrl} 
劉雅甄 & \multicolumn{2}{l}{} \\
中華大學 & 體育室 \\
聯絡住址 & $:$ & 300 台灣新竹市五福路二段707號 \\
聯絡電話 & $:$ & $03-5186196$ \\
傳真電話 & $:$ & $03-5186450$ \\
E-mail & $:$ & yazhen@chu.edu.tw
\end{tabular}

